\title{
National Postal Strategies after a Full Postal Market Opening
}

\author{
Gonzales D'ALCANTARA
}

University of Antwerpen and d'Alcantara Economic Consulting

\section{Axel Gautier}

HEC, Université de Liège and CORE, Université Catholique de Louvain, Belgium

Published in Michael A. Crew and Paul R. Kleindorfer, (2008). Competition and Regulation in the Postal and Delivery Sector, Edward Elgar, Northampton, MA, USA and Cheltenham, UK.

\section{Introduction}

In October 2006 the European Commission presented to the European Parliament and the Council of Ministers a proposal for a Directive ${ }^{1}$ modifying Directive $97 / 67 / \mathrm{CE}^{2}$ and $2002 / 39 / \mathrm{EC}^{3}$ to open fully the Postal market in the European Union by January 1, 2009. In a vote on the proposal and amendments on July 11, 2007, the European Parliament accepted this proposal with a few additional conditions, but postponing the date to 2011-13 (with most of the EU-15 members subject to the 2011 date and new members and countries like Greece facing special conditions subject to the 2013 date). The proposal will now go forward to the Council of Ministers for approval. This proposal requires Full Postal Market Opening (FMO) in all EU member states and the obligation for all member states to provide a Universal Postal Service, including postal delivery every day, to every address and at an affordable price. The proposal foresees the possibility that losses for a National Postal Operator (PO) as a result of its Universal Service Obligation (USO) may need to be financed by various means, including a state subsidy.

Let us assume that this Directive is accepted and that, within this context, all member states have to specify a well-defined USO, a corresponding financing mechanism and regulatory constraints. Such specifics will result from a national decision process involving three national players: the Incumbent (I) or historical Universal Service Provider (USP), an Entrant and a National Policy Maker (Regulator). We assume that the Regulator has the power to determine both USO and Regulatory constraints on the USP, within the setup defined by the FMO, and has the budgetary capacity to pay USO related subsidies, either directly or through a competition fund, needed by the USP to reach balanced accounts.

In the postal sector, a main driver of delivery costs is the density of delivery points. Boldron et al. (2006) estimate the cost of delivery on the basis of Population Density, the Grouping Index (the ratio between the number of delivery points and the number of stop points) and the mail volume. Boldron et al. undertook their analysis at a rather detailed level, based on relatively small delivery areas, and their results exhibit large variations in delivery costs across and within countries. The approach adopted in this present paper extends their analysis and shows how, why and to what extent different cost structures at the delivery route level (referred to below as route-cost profiles) are likely to give rise to different dynamics of Market Entry under FMO.

We assume a duopoly between the Incumbent and an Entrant, and we show that different route cost structures have very different consequences under FMO. For example, if unit delivery costs were the same for all routes, the USP would have little difficulty fending off an 
Entrant of roughly the same efficiency level. However, if the USP has some urban routes that are low cost and many rural routes that are high cost, then FMO can be expected to give rise to cream skimming by the Entrant (E) as analyzed by many previous authors (See, e.g., Crew and Kleindorfer (2005) and d'Alcantara and Amerlynck (2006) for a discussion of earlier contributions). While these two examples of route-cost structures do not exhaust the interesting possibilities, they do point to the central role of postal route-cost structures in predicting the outcome of FMO. The main point of our analysis here is to summarize the consequences of FMO in varying environments as captured in different route-cost profiles. We do this both theoretically, through a general duopoly model, and for 5 illustrative cases that are derived in part from empirical literature on existing national operators in the EU, as summarized by Boldron et al. (2006).

In the duopoly modeled here between an Entrant and the USP, the USP must serve all addresses while $\mathrm{E}$ is free to cover a limited portion of the territory. The model is a pure bypass model: E builds up its own delivery network and does not buy access from the USP. Firms compete with a single product («average mail») that the USP must sell at a uniform price.

Our results show a large diversity of outcomes after FMO. We first consider three different distributions of the route costs keeping the total cost constant (as well as the pre-FMO breakeven tariff). Depending on the distribution of costs, E coverage of market ranges from 3.5\% (Homogenous Route cost profile) of the addresses to 45.4\% (Dual Route cost profile). These differences are solely the result of different structures for the route costs within the stylized countries analyzed.

In the Homogenous Route cost profile, the universal service can be sustained without any safeguarding measures and, if prices are regulated, the price increase is rather limited. In the Dual Route cost profile, the rise in the USP unit cost (due to entry) is such that the USO cannot be sustained without state subsidies, even if the USP has complete freedom to set its price (except for the uniform price constraint that is part of the USO). In an intermediate case (Homogenous Route cost profile), the USP makes losses after FMO if prices are set at the welfare maximizing level. These losses resulting from the USO under FMO can be financed by state subsidies, by a pay or play mechanism or by removing price regulation.

We then consider then two configurations where most of the routes are in a low cost (urban) area and in a high cost (rural) area, respectively. In the Dense Stop Point Route profile, E covers most of the addresses without threatening the financial stability of the USP and the viability of the USO. In the Non-Dense Stop Point Route profile, E picks only the most profitable routes and, despite a limited geographical coverage, the USO cannot be sustained without subsidies. Taken together, these results show that different country configurations lead to different outcomes after FMO and that different solutions for USO financing are also dictated by different route-cost profiles.

This paper is organized as follow. Section 2 contains a brief description of the model, details of which may be found in the technical appendix. In section 3, we provide details of the calibration of our simulation model, whose results are presented in section 4 . Section 5 concludes.

\section{The Model}




\subsection{Summary of the Model}

We consider two firms: the Incumbent PO (I) and an Entrant (E). The two firms compete for an average mail product. The model is a pure bypass model: firm E builds up its own delivery network and is engaged in facility-based competition with I. A USO is imposed by the Regulator on I. The USO constraints include a geographically uniform tariff, the obligation to serve all the customers and other obligations such as frequency of delivery, that imposed costs on the PO. E is not subject to the same constraints and is not required to cover the whole territory. There is no possibility of access in this model. This means that E cannot achieve universal coverage by buying access to I's delivery network for the addresses that it does not cover. While the assumption of no access may seem extreme, it allows a clean representation of the results of route-cost profiles and accords with the business models of several existing markets (e.g., Sweden) where competitors begin their entry by serving specific regions, choosing their customers to be those that only are interested in delivery in the areas served by these competitors. Note that customers in our model can use the services of both E and I, sorting their mail out according to the delivery route coverage of these two service providers.

We decompose the postal value chain in two main activities: upstream activities and delivery. Upstream activities include mail collection, mail transport and sorting. Upstream activities are operated under constant returns to scale. Delivery is an increasing returns to scale activity and it involves both fixed and variable costs. In this model, we consider a fixed delivery cost per address.

There are $\mathrm{N}$ addresses in the country. We rank these addresses according to their fixed delivery cost. In the graphs below the address on the left has the lowest fixed delivery cost, the address on the right has the highest. The main driver of the fixed delivery costs is the Delivery Stop Point Density. This means that if E and I can have a different delivery cost per address, the ranking of addresses according to their cost is the same because they both depend on the observed height of the buildings, quantified using the Grouping Index.

We define a demand per-address that is the number of mail items sent to address $n$. We make the assumption that this demand only depends on prices. This means in particular that 1) the demand is independent of the receiver's location. 2) The demand addressed to E does not depend on its market coverage i.e. there is no network effect. And 3) given that I is subject to a uniform tariff constraint, E serves first the addresses with the lowest delivery cost.

According to the bypass decision of $\mathrm{E}$, some addresses are served by two firms while others are served only by I. If $\mathrm{E}$ does not cover the whole territory, a sender that uses E's mail service must pre-sort its mailing in order to consign to $\mathrm{E}$ only the mailing with a covered address. $^{4}$

The welfare is the sum of the total consumer surplus net of the senders' expenses and the firms' profits. In case the profit of the USP is negative, subsidies must be paid and their net cost must be subtracted from welfare. Subsidies have a shadow cost, meaning that transferring one Euro to the USP reduces the welfare by more then one euro.

\subsection{A four-stage process}

In a first stage, we consider that a Monopoly situation prevails before FMO and we search for the price that maximizes welfare while guaranteeing that the USP manages to cover the costs 
of the USO with its profits. In a second stage, we evaluate the consequences of FMO when the USP continues to sell its product at the pre-FMO price. E invests in an alternative Postal Distribution Network with a freely chosen frequency of delivery and freely chosen distribution zones i.e. $\mathrm{E}$ is not bound by any universal coverage constraint. The firms then compete for mail volumes posted to a limited number of addresses. Given that the demand is independent of the location, E covers first the low cost addresses. As a matter of fact, the region covered by $\mathrm{E}$ is such that $\mathrm{E}$ realizes a zero margin on the last covered address. Because delivery exhibits increasing returns to scale and density, the entry of a competitor increases the unit cost of delivery for the USP by eroding its volumes. The consequence is that the USP is unable to finance universal coverage at a uniform price with the pre-FMO tariff. In this case, the Regulator must pay a subsidy to the USP, as authorized by the proposed European Postal Directive.

In a third stage, we analyze the possibility that the Regulator prefers to reduce or eliminate the subsidy of stage 2 by allowing the USP to set its tariff freely. This also leads to changes in price and market coverage of $\mathrm{E}$, which is assumed to be a price follower in a von Stackelberg price game. Finally, we consider a fourth stage where the Regulator imposes a price-cap on the USP. The price cap results from welfare optimization by the Regulator and may still leave the need for subsidies to attain break-even operations.

It is necessary to note a number of limitations of the model presented. The USO constraints imposed on the USP, as defined by the Commission Proposal, include a geographically uniform tariff, the obligation to serve all the customers and obligations in term of frequency of delivery. We assume that uniformity applies for the standard average letter mail to which we restrict our analysis here. Assuming uniform tariffs for a single product is neither general nor realistic. In practice, uniform tariffs will be imposed only on Single Piece Letter Mail, not on Bulk mail, but Bulk mail does use the same delivery network as Single Piece Letter Mail. This aspect is not considered here and has to be taken into account when assessing the final results and calibrations. Finally, the model is a pure bypass model and we therefore neglect the possibility that competition remains limited to the upstream segments of the market with competitors buying mail delivery to I. So our model can only explain one form of competition (bypass) and neglects the other (access or worksharing). In countries where $\mathrm{E}$ has a limited coverage of the addresses because the Delivery costs per addresses are high, our model predicts little competition after FMO. In reality, in these countries competition can be substantial but limited to the upstream market segments. ${ }^{5}$ Taking this possibility into account would give us a clearer picture of market situations after FMO, but would obviously lead to a more complicated model.

\section{Model calibration}

\subsection{Parameter values}

We calibrate our model and generate numerical results to evaluate quantitatively the extent of entry and the consequences of FMO on welfare. For our numerical exercise, we derive a system of linear demand equations from the maximization of the utility of a representative

sender defined as: $U\left(x_{I}, x_{E}\right)=\alpha_{I} x_{I}+\alpha_{E} x_{E}-\beta_{I} \frac{x_{I}^{2}}{2}-\beta_{E} \frac{x_{E}^{2}}{2}-\delta x_{I} x_{E}$

Where $x_{I}$ and $x_{E}$ are the number of postal items sent to address $n$ with I and E respectively. 
We use the following elements to calibrate the demand functions: (1) we consider that a monopoly USP faces a demand of 200 postal items per household if it charges a price of $0.40 €$ and (2) at this price/mailing volume, the elasticity of the monopoly demand is -0.4 . When the two firms compete, we assume that (3) the displacement ratio is equal to 0.9 meaning that $90 \%$ of the mails proceeded by E were previously carried by the USP, (4) at identical prices, the mail volume per address carried by $\mathrm{E}$ is equal to $20 \%$ of the Incumbent's volume and (5) with a $20 \%$ price discount, $\mathrm{E}$ has a mailing volume per address equal to that of I. The parameters used to calibrate this model are similar to the ones used by De Donder, Cremer, Dudley and Rodriguez (2006). The hypothetical country we consider has a population of 2 million households with an average household size of 2.5 persons.

Households and companies, this means addresses, are grouped into routes which are ranked according to their fixed cost of delivery. We generate upstream and downstream costs for two postal regions with extreme postal densities: a "most dense" (urban) region and a "most nondense" (rural) one. These regions differ according to the number of delivery points per stop (Grouping Index) and the distance between two stops in each route. Consequently delivery method differs in the two regions. We generate values for the delivery costs using the best practice cost model developed in d'Alcantara and Amerlynck (2006) with hypothetical country data defined above and factor costs equal to the average across European Union Countries in Euros for 2005. Best technology includes different distribution modes in the two types of areas. By foot $90 \%$, by bicycle $9 \%$ and by car $1 \%$ in the "most dense" (urban) area; by foot $1 \%$, by bicycle $9 \%$ and by car $90 \%$ in the "most non-dense" (rural) area. The "most dense" region has a Grouping index of 15, which corresponds to a reasonable higher limit for this index (Boldron, Joram, Martin and Roy, 2006). The "most non-dense" region has a Grouping Index of 1. Our resulting unit cost estimates are given in Table 1.

\begin{tabular}{|lcc|}
\hline Configuration of Stop Points & Non-dense & Dense \\
& & \\
USP unit cost & 0.520 & 0.230 \\
Upstream unit cost USP & 0.185 & 0.185 \\
Delivery unit cost USP Urban & - & 0.045 \\
Delivery unit cost USP Rural & 0.335 & - \\
\hline
\end{tabular}

Table 1: Unit costs derived using the best practice cost model

Reported on an annual basis, the delivery cost of one address in the postal "most dense" region is equal to $9 €(0.045 €$ per unit $)$ and it increases to $67 €(0.335 €$ per unit) in the postal "most non-dense" region. These costs are considered to be fixed i.e. independent of the mailing volume. The estimated variable costs is equal to $0.185 €$ per letter and it is independent of the delivery point.

We consider that $\mathrm{E}$ is more cost effective than the USP. In particular, both the fixed cost peraddress and the variable cost per mail are assumed to be equal to $80 \%$ of USP's cost. A lower frequency of delivery could explain such a cost differential, but so could labor cost differentials between $\mathrm{E}$ and $\mathrm{I}$.

\subsection{Typical country configurations}

We then generate the five possible Route Cost profiles representing five typical country configurations shown in Figure 1. For the case of Monotone Differentiated Route cost profile, the delivery cost per address is monotonically and linearly increasing from the lowest 
value to the highest value corresponding to addresses located in Stop Points with decreasing density. For a Dual Route cost profile, $40 \%$ of the addresses are located in Stop Points with a constant high density, and $40 \%$ are located in Stop Points with a constant low density. The remaining addresses have a delivery cost which is monotonically increasing between these extreme values. In the case of a Homogenous Route cost profile, $80 \%$ of the addresses have a delivery cost equals to the average cost between rural and urban cost. The remaining costs per address are monotonically increasing from the lowest value to the average and from the average to the highest. The three configurations introduced are symmetric, meaning that the average delivery cost per address is $38 €$ and hence, the total fixed cost for the USP is identical. The two next configurations are non-symmetric. In the case of the Dense Stop Point Route cost profile, $60 \%$ of the addresses are in a constant high postal density zone, while for the Non-dense Stop Point Route cost profile, $60 \%$ of the addresses are in a constant low postal density zone. In both cases, for the remaining addresses, the delivery cost is monotonically increasing respectively up to the highest value and starting from the lowest value. These two Route Cost profiles result in respectively a lower and a higher total delivery cost than the other three configurations. The distributions of fixed cost per-address within the national population of postal destinations are represented in Figure 1.

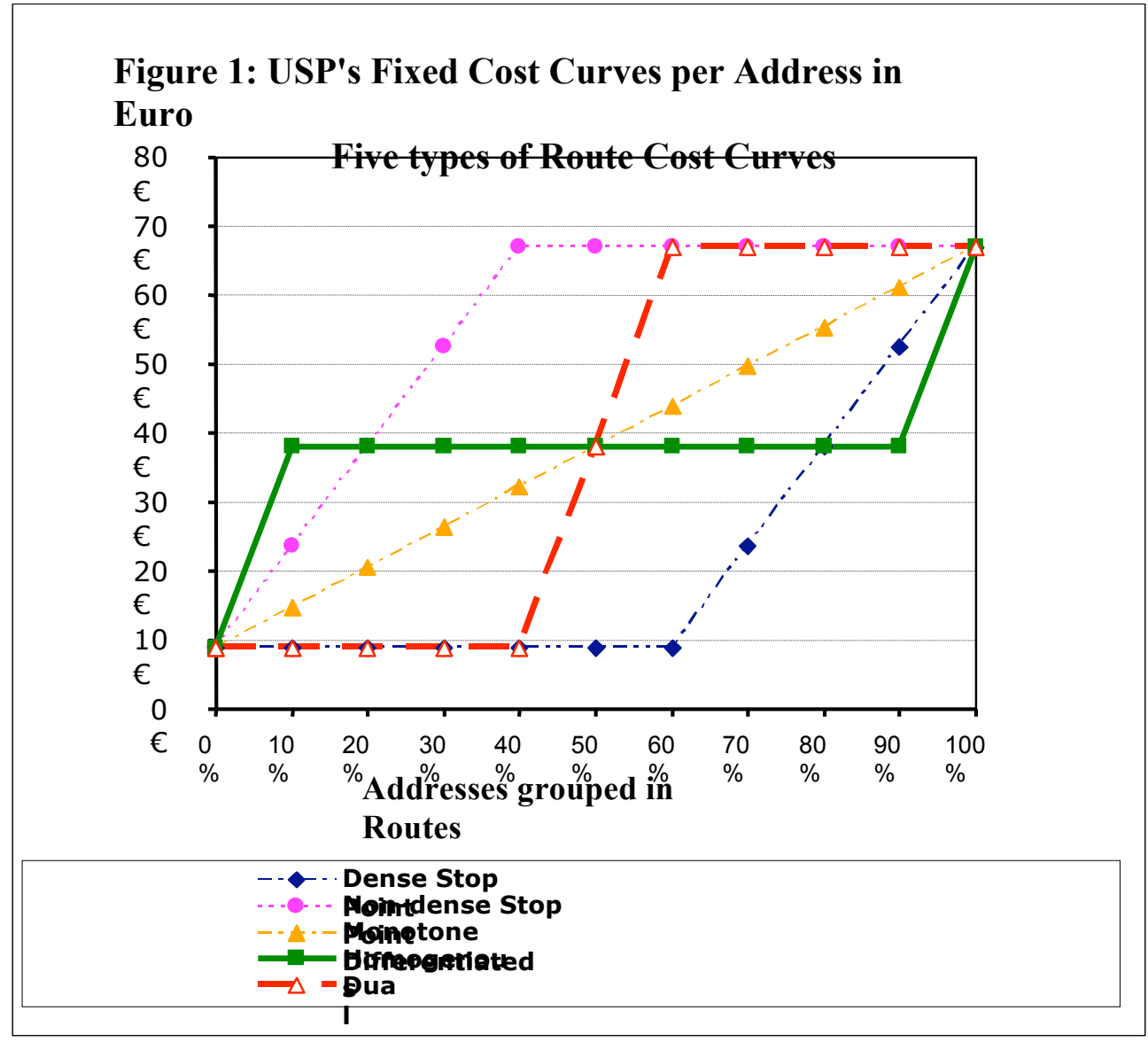

\section{Simulation results}

For each of the 5 Route Cost profiles, we generated 4 different sets of prices and other market results. The first scenario considered refers to the situation where the USP operates as a monopolist. In this monopoly case, the USP price is regulated and set at the break-even point. The second set of result corresponds to the situation where the market is opened to competition and where the USP continues to apply the pre-FMO price. Then, we adapt the 
prices to competition and we present the unregulated USP prices that maximize the firm's profit and the regulated USP prices that maximize the welfare. For each configuration, we report the prices $\left(p_{I}, p_{E}\right)$, the market coverage of $E,(n)$, the mail volume per address in the one-operator $\left(x_{I}^{M}\right)$ and the duopoly zones $\left(x_{I}^{D}, x_{E}^{D}\right)$, the profits and welfare and the subsidy to the USP. Subsidies are evaluated at a shadow cost of 0.3., meaning that transferring one Euro to the USP reduces welfare by 1.3 Euros.

\subsection{General overview}

The 5 typical country configurations generate different outcomes after FMO. To mention few striking figures, we observe that the market coverage of $\mathrm{E}$ is extremely limited in the Homogenous route case (no more than 10\%) while it is substantial in the Dual (at least $45 \%$ ) and the Dense Stop Point Route case (at least 65\%). If prices are capped after FMO, consumers do not face high price increase since the highest is limited to 4 Eurocents. Even in one case (the Non-Dense Stop Point Route), the price decreases after FMO. The reason for that decrease in price is the misalignment between prices and costs for the low costs addresses where the firms compete. Despite a limited price increase, the USO financing is threatened in 3 route configurations. In the Dual and the Dense Stop Point Route cases, it is not possible to maintain the USO without subsidies. And these subsidies could be quite high (up to $10.57 €$ per address). In the Monotone Differentiated Route case, the regulator has more options to finance the USO after FMO. We show that a pay-or-play mechanism, removing price regulation or state subsidies can all be used to finance the USO with different welfare impact.

\subsection{Graphical analysis}

The 5 typical country configurations can also been overviewed in a graphical way. Figure 2-6 show Unit Cost Curves before FMO corresponding to the 5 Route Cost profiles. These Figures should be interpreted exactly like Figure 1 except that fixed cost per address is replaced by unit costs per address and that the Uniform USP price of the average product can be shown in the same Figure. At a given price, E captures a fraction of the mails sent to the covered addresses. This results in a per-address profit for E. E covers all the addresses for which the fixed delivery cost is smaller than the per-address profit. Clearly the two main determinants of market coverage by E are (1) the price charged by the USP who affects the per-address profit and (2) the distribution of the fixed cost per-address. These two factors explain the observed differences in market coverage and in the mail volume of $\mathrm{E}$.

The Uniform price set by the USP at the first stage of the process and the final results of market coverage for Es obtained in the fourth stage, with FMO under Welfare Maximizing Prices, are shown on each Figure. The dark areas at the bottom left hand side of these Figures correspond to the mail volume share of $\mathrm{E}$ within his coverage. The size of his coverage $\%$ is given by extreme the right hand side point of this dark area at the bottom of the Figure. 

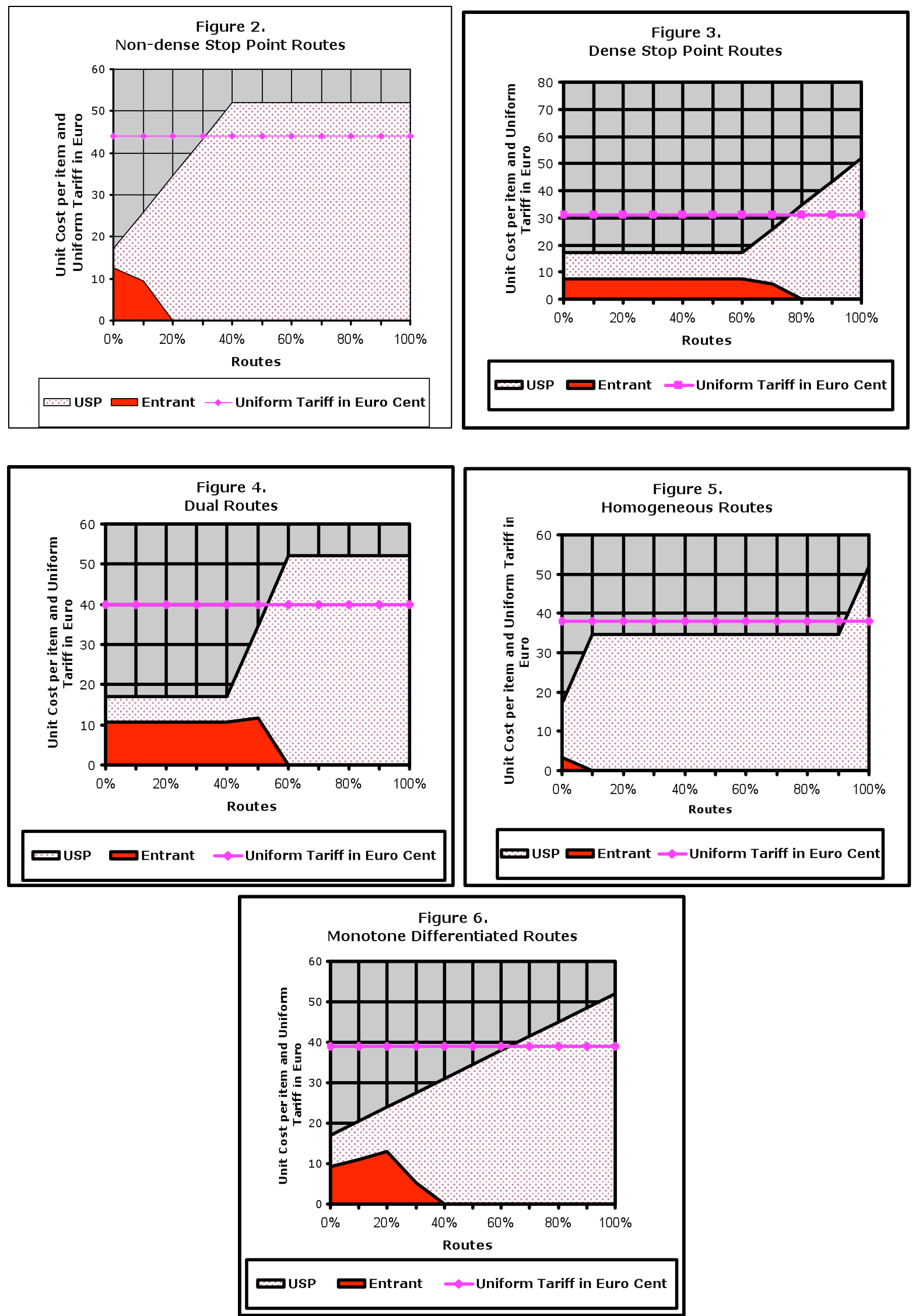

4.3. Symmetric country configurations: Monotone Differentiated, Dual and Homogenous Route profiles 
It is interesting to start our analysis by these three symmetric cases because these three route cost profiles have the same total delivery cost. Hence, the price charged by a regulated monopoly USP is the same $(0.37 €)$ and so is welfare.

\begin{tabular}{|c|c|c|c|c|}
\hline & Tab & 2: Monotone Differ & rentiated Route Co & rofile \\
\hline Total fixe & $d$ cost USP* & & & ${ }^{*}$ in million euros \\
\hline & $\begin{array}{c}\text { Monopoly } \\
\text { USP }\end{array}$ & $\begin{array}{c}\text { FMO with } \\
\text { constant USP price }\end{array}$ & $\begin{array}{c}\text { FMO. profit } \\
\text { maximizing prices }\end{array}$ & $\begin{array}{c}\text { FMO. Welfare } \\
\text { maximizing prices }\end{array}$ \\
\hline $\mathrm{p}_{\mathrm{I}}$ & 0.37 & 0.37 & 0.43 & 0.39 \\
\hline $\mathrm{p}_{\mathrm{E}}$ & 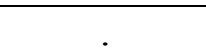 & 0.27 & 0.32 & 0.30 \\
\hline $\mathrm{X}_{\mathrm{I}}^{\mathrm{M}}$ & 206 & 206 & 193 & 200 \\
\hline $\mathrm{x}_{\mathrm{I}}^{\mathrm{D}}$ & & 100 & 79 & 98 \\
\hline $\mathrm{x}_{\mathrm{E}}^{\mathrm{D}}$ & . & 117 & 127 & 113 \\
\hline $\mathrm{n}$ & . & $351601(17.5 \%)$ & $653664(32.6 \%)$ & $472004(23.5 \%)$ \\
\hline$\Pi_{I}^{*}$ & 0 & -6.82 & 1.03 & -1.19 \\
\hline$\Pi_{\mathrm{E}}{ }^{*}$ & 0 & 1.43 & 4.95 & 2.58 \\
\hline Welfare $^{*}$ & 212 & 204 & 199 & 204 \\
\hline Subsidy $^{*}$ & 0 & 6.82 & 0 & 1.19 \\
\hline
\end{tabular}

\begin{tabular}{|c|c|c|c|c|}
\hline \multicolumn{5}{|c|}{$\begin{array}{l}\text { Table 3: Dual Route Cost Profile } \\
\end{array}$} \\
\hline \multicolumn{4}{|c|}{ Total fixed cost USP* 76} & \multirow{2}{*}{$\begin{array}{c}{ }^{*} \text { in million euros } \\
\text { FMO. welfare } \\
\text { maximizing prices }\end{array}$} \\
\hline & $\begin{array}{c}\text { Monopoly } \\
\text { USP }\end{array}$ & $\begin{array}{c}\text { FMO with } \\
\text { constant USP price }\end{array}$ & $\begin{array}{c}\text { FMO. profit } \\
\text { maximizing prices }\end{array}$ & \\
\hline $\mathrm{p}_{\mathrm{I}}$ & 0.37 & 0.37 & 0.45 & 0.40 \\
\hline $\mathrm{p}_{\mathrm{E}}$ & & 0.28 & 0.31 & 0.29 \\
\hline $\mathrm{x}_{\mathrm{I}}^{\mathrm{M}}$ & 206 & 206 & 188 & 198 \\
\hline $\mathrm{x}_{\mathrm{I}}^{\mathrm{D}}$ & & 100 & 52 & 78 \\
\hline $\mathrm{x}_{\mathrm{E}}^{\mathrm{D}}$ & . & 117 & 151 & 132 \\
\hline $\mathrm{n}$ & . & $870320(43.5 \%)$ & $960832(48 \%)$ & $908685(45.4 \%)$ \\
\hline$\Pi_{I}^{*}$ & 0 & -16.90 & -9.24 & -11.57 \\
\hline$\Pi_{\mathrm{E}}^{*}$ & 0 & 6.81 & 16.42 & 10.77 \\
\hline Welfare ${ }^{*}$ & 212 & 187 & 185 & 189 \\
\hline Subsidy $^{*}$ & 0 & 16.9 & 9.24 & 11.57 \\
\hline
\end{tabular}

\begin{tabular}{|c|c|c|c|c|}
\hline & & Table 4: Homogeno & Route Cost Profile & \\
\hline Total fix & cost USP*: & & & ${ }^{*}$ in million euros \\
\hline & $\begin{array}{c}\text { Monopoly } \\
\text { USP }\end{array}$ & $\begin{array}{c}\text { FMO with } \\
\text { constant USP price }\end{array}$ & $\begin{array}{c}\text { FMO. profit } \\
\text { maximizing prices }\end{array}$ & $\begin{array}{c}\text { FMO. welfare } \\
\text { maximizing prices }\end{array}$ \\
\hline $\mathrm{p}_{\mathrm{I}}$ & 0.37 & 0.37 & 0.48 & 0.375 \\
\hline $\mathrm{p}_{\mathrm{E}}$ & . & 0.28 & 0.29 & 0.28 \\
\hline $\mathrm{x}_{\mathrm{I}}^{\mathrm{M}}$ & 206 & 206 & 182 & 205 \\
\hline $\mathrm{x}_{\mathrm{I}}^{\mathrm{D}}$ & & 100 & 34 & 98 \\
\hline $\mathrm{x}_{\mathrm{E}}^{\mathrm{D}}$ & . & 117 & 164 & 118 \\
\hline $\mathrm{n}$ & . & $70320(3 \%)$ & $200000(10 \%)$ & $74403(3.5 \%)$ \\
\hline$\Pi_{I}^{*}$ & 0 & -1.36 & 25.5 & 0 \\
\hline$\Pi_{\mathrm{E}}^{*}$ & 0 & 0.28 & 2.32 & 0.32 \\
\hline Welfare ${ }^{*}$ & 212 & 210 & 197 & 211 \\
\hline Subsidy $^{*}$ & 0 & 1.36 & 0 & 0 \\
\hline
\end{tabular}


But FMO has different consequences in these three country configurations. In the case of FMO with constant USP price, the market coverage of E ranges from $3 \%$ of the addresses in the Homogenous Route Cost Profile (Table 4) to $43.5 \%$ in the Dual Route Cost Profile (Table 4). The market coverage of $\mathrm{E}$ depends on the shape of the delivery cost per address function. When it steeply increases (Homogenous Route cost profile), the coverage is limited. With a smoothly increasing function, the coverage becomes more substantial and in the limit case of a flat delivery cost per address function (Dual and Dense Stop Point route cost profile), E coverage is extremely important since it consists of the flat zone and a fraction of the Routes with increasing cost.

In all the cases, with unchanged prices, the entry of a new firm results in losses for the USP, losses that must be compensated with subsidies. In the dual route case, where $\mathrm{E}$ has a high market coverage, the subsidies is more than $8 €$ per address.

Consider the optimal reaction after FMO. From the above Tables, we see that in all configurations, both the unregulated and the regulated prices increase compared to the monopoly situation. This means that tariffs of $\mathrm{E}$ and of the Incumbent are strategic complements: when the tariff of I increases, the tariff of $\mathrm{E}$ follows by increasing as well. Consequently, the price charged by E and its market coverage increase too. But the magnitude of the price increase depends on the configuration. In all cases, the optimal price increase does not exceed $0.03 €$. But, this limited price increase imposes that to finance the universal coverage by I, the Regulator intervenes in USO financing through subsidies. This holds true except in the homogenous route case where E's market coverage is limited and the USP manages to break even at regulated prices after FMO.

Now compare these regulated prices with the prices that the USP would have charged in the absence of regulation. Price increases are limited by the fact that higher prices imply higher market share and higher market coverage by E. For example in the homogenous route case any further price increase would increase the market coverage from $10 \%$ to $90 \%$ of the addresses. The reaction of E explains why we observe different price differentials between regulated and non-regulated prices. Welfare consequences of relaxing regulatory price restrictions are also different and particularly important in the homogenous route case where a large price increase is imposed on captive customers.

In the Dual Route Cost case, the market coverage of $\mathrm{E}$ is close to $50 \%$. Moreover, with regulated prices, it is in this configuration that $\mathrm{E}$ has the highest market share in the duopoly region. Consequently, in this configuration, the mail volume of the Incumbent falls considerably as illustrated in the following table.

\begin{tabular}{|c|c|c|c|}
\hline Mail volume & Monotone differentiated & Dual & Homogenous \\
\hline USP & 353.07 & 287.72 & 402.51 \\
\hline Entrant & $53.53(13.2 \%)$ & $120.78(29.6 \%)$ & $8.84(2.2 \%)$ \\
\hline Total & 406.60 & 408.51 & 411.36 \\
\hline
\end{tabular}

Table 5: Total mail volume after FMO, in millions of items

\begin{tabular}{|c|c|c|c|}
\hline Monopoly USP & Monotone differentiated & Dual & Homogenous \\
\hline 0.37 & 0.40 & 0.44 & 0.37 \\
\hline
\end{tabular}

Table 6: Average cost of the USP in the monopoly case and after FMO 
This fall in volume increases the average cost of the mail (Table 6). This holds true in all configurations, with the specificity that in the Dual route case, it is impossible to find a price that would guarantee a non-negative profit for E. The important decline in I's mailing volume - E carries a third of all mails while it covers less than a half of the territory - and the associated rise in the average cost is such that there does no longer exist a price such that I breaks-even. This impossibility to find a price for the USP compatible with a non-negative positive profit is referred to as a graveyard spiral (Crew and Kleindorfer, 2005). As illustrated in these three examples, the need for subsidies after FMO potentially depends on the Route Cost country configuration.

\subsection{Non-symmetric distributions: Dense and Non-Dense Stop Point Route cost profiles.}

In the Dense Stop Point Route cost case, the country is mainly urban and the total delivery cost and the average cost in the monopoly case $(0.27 €)$ are the lowest. Conversely, in the Non-dense Stop Point Route cost case, the average cost for a monopoly USP $(0.49 €)$ and the total cost are the highest.

\begin{tabular}{|c|c|c|c|c|}
\hline Total fixe & $\begin{array}{r}\text { Tal } \\
\text { cost USP* }\end{array}$ & $\begin{array}{l}\text { le 7: Non-dense Stop } \\
10.8\end{array}$ & Point Route Cost P & ${ }^{\mathbf{e}}{ }^{*}$ in million euros \\
\hline & $\begin{array}{c}\text { Monopoly } \\
\text { USP }\end{array}$ & $\begin{array}{c}\text { FMO with } \\
\text { constant USP price }\end{array}$ & $\begin{array}{c}\text { FMO. profit } \\
\text { maximizing prices }\end{array}$ & $\begin{array}{c}\text { FMO. welfare } \\
\text { maximizing prices }\end{array}$ \\
\hline $\mathrm{p}_{\mathrm{I}}$ & 0.49 & 0.49 & 0.50 & 0.44 \\
\hline $\mathrm{p}_{\mathrm{E}}$ & & 0.33 & 0.33 & 0.31 \\
\hline $\mathrm{x}_{\mathrm{I}}^{\mathrm{M}}$ & 182 & 182 & 180 & 190 \\
\hline $\mathrm{x}_{\mathrm{I}}^{\mathrm{D}}$ & & 33 & 29 & 57 \\
\hline $\mathrm{x}_{\mathrm{E}}^{\mathrm{D}}$ & . & 165 & 168 & 148 \\
\hline $\mathrm{n}$ & . & $402276(20 \%)$ & $424350(21 \%)$ & $300732(15 \%)$ \\
\hline$\Pi_{I}^{*}$ & 0 & -18.20 & -18.81 & -21.41 \\
\hline$\Pi_{\mathrm{E}}^{*}$ & 0 & 4.7 & 5.22 & 2.62 \\
\hline Welfare $^{*}$ & 165 & 135 & 133 & 138 \\
\hline Subsidy $^{*}$ & 0 & 18.2 & 18.81 & 17.36 \\
\hline
\end{tabular}

\begin{tabular}{|c|c|c|c|c|}
\hline \multicolumn{5}{|c|}{ Table 8: Dense Stop Point Route Cost Profile } \\
Total fixed cost USP $: 41.2$ & ${ }^{*}$ in million euros \\
\hline & $\begin{array}{c}\text { Monopoly } \\
\text { USP }\end{array}$ & $\begin{array}{c}\text { FMO with } \\
\text { constant USP price }\end{array}$ & $\begin{array}{c}\text { FMO. profit } \\
\text { maximizing prices }\end{array}$ & $\begin{array}{c}\text { FMO. welfare } \\
\text { maximizing prices }\end{array}$ \\
\hline $\mathrm{p}_{\mathrm{I}}$ & 0.27 & 0.27 & 0.39 & 0.31 \\
\hline $\mathrm{p}_{\mathrm{E}}$ &. & 0.23 & 0.28 & 0.24 \\
\hline $\mathrm{x}_{\mathrm{I}}{ }^{\mathrm{M}}$ & 224 & 224 & 188 & 217 \\
\hline $\mathrm{x}_{\mathrm{I}}{ }^{\mathrm{D}}$ & & 152 & 83 & 129 \\
\hline $\mathrm{x}_{\mathrm{E}}{ }^{\mathrm{D}}$ & $\cdot$ & 79 & 130 & 98 \\
\hline $\mathrm{n}^{*}$ & $\cdot$ & $1211830(65 \%)$ & $1405130(70 \%)$ & $1262730(65 \%)$ \\
\hline$\Pi_{\mathrm{I}}{ }^{*}$ & 0 & -7.98 & 8.19 & 0 \\
\hline$\Pi_{\mathrm{E}}{ }^{*}$ & 0 & 0.82 & 15.49 & 4.47 \\
\hline Welfare $^{*}$ & 252 & 239 & 240 & 247 \\
\hline Subsidy & 0 & 7.98 & 0 & 0 \\
\hline
\end{tabular}


In the Non-dense Stop Point Route cost case, a majority of addresses are located in the high cost rural zone. Consequently, to cover the fixed cost of delivery - which is the highest of all configurations - a monopoly USP must set a high letter price. At first, it seems that this configuration would deter $\mathrm{E}$ to invest in a large delivery network. But this is countervailed by the high price charged by I. A high price allows E to capture a large mail volume and to realize a high margin on its sales. Hence, E could have a large profit per-address and the market coverage is substantial.

After FMO, the Regulator faces the following dilemma: either it increases the price - which further increases the mail unit cost because E reacts by extending its market coverage - or it decreases the price and the mail unit cost. In our numerical simulations, we found that the optimal regulatory response is a slight price decrease, which has a consequent impact on E's market coverage.

In the Dense Stop Point Route cost case, a majority of the addresses are located in the low cost urban zone. At first, it seems that this configuration is the most favorable to E because the delivery costs are low. But, this uniformity in delivery conditions implies that the monopoly price necessary to break-even is low. Therefore, E has a low margin on its sales, and its mail volume is limited too. A low profit per-address generates large scale entry only if the margin is high enough to cover the urban delivery cost. If this is the case, the market coverage of $\mathrm{E}$ is at least the urban zone (60\% of the addresses). In the Dense Stop Point Route cost case, the entry decision is dependent on the mail demand configuration and on the possibility to achieve a sufficient margin to cover the fixed delivery cost in the urban region. This is hampered by the low price charged by I.

Mail volumes and market shares in the Dense and Non-dense Stop Point Route cost cases are given in table 9. Despite the highest coverage in the Dense Stop Point Route Cost Profile, the market share of $\mathrm{E}$ is not the highest of all cases because low price by I makes mail capture more difficult.

\begin{tabular}{|c|c|c|}
\hline Mail volume & Dense Stop Point Route cost & Non-dense Stop Point Route cost \\
\hline USP & 322,87 & 340 \\
\hline Entrant & $123.74(27,7 \%)$ & $44,5(11,57 \%)$ \\
\hline Total & 446.62 & 384,51 \\
\hline
\end{tabular}

Table 9: Total mail volume after FMO, in million items

\subsection{USO financing after FMO}

Let us compare the results for our Route Cost Profiles in the fourth and final stage with FMO under welfare maximizing prices. In Table 10 we have ordered the results for five Route Cost Profiles starting with the highest USP tariff results. We compare USP Tariffs, Entrant's Coverage, the Subsidy per address to be paid by the Regulator and the ratio between this Subsidy and E's Profit.

Non-dense Stop Point Route Cost

Dual Route Cost situation

Monotone differentiated Route Cost

Homogenous Route Cost situation

$\begin{array}{ccc}\begin{array}{c}\text { Tariff } \\ \text { USP }\end{array} & \begin{array}{c}\text { Coverage } \\ \text { E }\end{array} & \begin{array}{c}\text { Subsidy/ } \\ \text { address }\end{array} \\ 0,44 € & 15.0 \% & 10.57 € \\ 0,40 € & 45.4 \% & 5.79 € \\ 0,39 € & 23.5 \% & 0,60 € \\ 0,38 € & 3.5 \% & 0,00 €\end{array}$

Subsidy/
Entrants' profit
6.6
1.1
0.5
0


It appears that high prices are associated with high subsidies. High prices and high subsidies mean that in these configurations, the cost of maintaining the USO is the greatest in a competitive market. Subsidy per address is the highest in the Dual and the Non-Dense Stop Point Route Cost Profiles though the market coverage by E differs. These two configurations have in common that a high fraction of the addresses are located in the rural region. In the monopoly case, the USO financing is possible through high cross-subsidies from the low cost addresses to the high cost ones. After FMO, these subsidies are no longer possible because E captures a large fraction of the mail sent to the low cost addresses. Mail capture is facilitated by the relatively high prices charged in these two configurations. In these two configurations, we clearly observe cream-skimming of the market by E. E captures a large fraction of the mail in the profitable region and leaves the non-profitable zones to I. Clearly USO financing is a major concern in this case.

In the Dense Stop Point and the Homogenous Route cost cases, no subsidy must be paid to the USP after FMO, even at welfare maximizing prices. But the mechanism at play is different. In the Dense Stop Point Route cost case, the market coverage of $E$ is substantial but its market share is limited due to low pricing by the USP (see Figure 3). This low pricing is feasible because there are few high cost addresses that must be subsidized (unlike the Dual Route cost case). In the Homogenous Route cost case, the market coverage of $\mathrm{E}$ is extremely limited. There are few profitable addresses for $\mathrm{E}$ and $\mathrm{E}$ captures only $2.2 \%$ of the total mail volume (table 5). Such a limited lost volume can easily be compensated with a slight price increase.

We finally report the ratio between the USO Subsidy and E's profit. If this ratio has the value one, this means that the amount of subsidy to be paid by the Regulator corresponds to the amount of E's profit. With a ratio of one or below, the Regulator can, instead of paying subsidies, establish a pay-or-play mechanism where $\mathrm{E}$ is required to contribute to the USO financing unless it satisfies the obligations itself (as is the case in Finland today ${ }^{6}$ ). With a ratio above one, a pay-or-play mechanism alone cannot be used to sustain the USO. Notice that, because subsidies are evaluated at a shadow cost of 0.3 , the welfare would be higher with a pay-or-play financing than with state subsidies.

\section{Concluding remarks}

With all the limitations of our model in mind - the use of a single average product model may be the greatest - we can conclude from this set of calibrations that, assuming FMO at the EU level, the results of the market outcomes will differ widely according to national configurations of delivery route costs. This means that both the requirements for a national USP Subsidy and the likely FMO bypass coverage of Es need to be studied in light of national route cost configurations. When the Regulator chooses a Price Cap to maximize national welfare, we find that the largest coverage by E appears in the "Dense Stop Point" and Homogenous Route cost situations and the smallest coverage in the Homogenous Route cost cases. We can also conclude no subsidy is due by the Regulator in the "Dense Stop Point" and the Homogenous Route cost cases and the Subsidy per address is highest in the "Non-dense Stop Point" and Dual Route cost cases. Finally we can conclude subsidies, where necessary or desirable, could be financed out of E's profits in the Dual Route Cost and Monotone Differentiated Route cost cases. In these instances the pay-or-play mechanism could be used as a way to finance the Universal Postal Service. 
Another set of calibrations should be made to explore the sensitivity of the results to various assumptions such as the displacement ratio, the shadow cost of subsidies, the relative cost effectiveness of $\mathrm{E}$ with respect to the USP and other inputs to this model.

Because different market outcomes are observed in our five typical configurations, our model calls for empirical research about the observed route cost profiles in EU member countries. Such research, together with extensions of the present model, should lead to greater insights about the consequences of FMO on both I POs and on the extent of competition likely to be established in various postal markets.

\section{Appendix: Model Structure}

\section{General assumptions and notation}

The model is a pure bypass model. Firm I (the incumbent) serves all addresses and firm E (entrant) is not bounded to universal coverage. Firms compete in price. The price game is a von Stackelberg price game where firm I decides first on its price.

Cost: We denote by $\mathrm{c}_{\mathrm{k}}$ the sum of all variable costs per mail proceeded by firm $k=I, E$. This cost includes the cost of all upstream activities and the variable cost of delivery. Delivery to address $n$ implies a fixed delivery cost. We rank the $\mathrm{N}$ addresses according to their fixed delivery cost. A function $F_{I}(n)$ represents the fixed delivery cost of I for delivery at address $\mathrm{n}$. The function $F_{I}(n)$ is such that $\partial F_{I}(n) / \partial n \geq 0$. The total delivery cost for I who must serve all addresses is: $\bar{F}_{I}=\int_{0}^{N} F_{I}(\tau) d \tau$. $\mathrm{E}$ is characterized by a fixed delivery cost per address $F_{E}(n)$. We assume that $\partial F_{E}(n) / \partial n \geq 0$, that is the fixed cost may differ between $\mathrm{E}$ and $\mathrm{I}$ but the ranking of addresses does not, because the ranking depends on delivery point density. The total fixed delivery cost for an Entrant who serves only the $n^{*}$ cheapest addresses is $\int_{0}^{n^{*}} F_{E}(\tau) d \tau$.

Demand: The demand for mail addressed to the receiver in $n$ is derived from the utility of a representative sender. Denote by $U\left(x_{I}, x_{E}\right)$, the utility of a sender that sends $x_{I}$ and $x_{E}$ mails to address $n$. We derive inverse demand functions by solving $\max _{x_{I}, x_{E}} U\left(x_{I}, x_{E}\right)-p_{I} x_{I}-p_{E} x_{E}$. If an address $n$ is only served by firm I, the corresponding monopoly inverse demand function is the found by solving $\max _{x_{I}} U\left(x_{I}, 0\right)-p_{I} x_{I}$. From these inverse demand functions, we define:

Monopoly demand: $x_{I}^{M}\left(p_{I}\right)$

Duopoly demands: $x_{I}^{D}\left(p_{I}, p_{E}\right)$ and $x_{E}^{D}\left(p_{I}, p_{E}\right)$

We assume that the products sold by firms I and $\mathrm{E}$ are imperfect substitutes.

Profit: When E covers the $n$ cheapest addresses, the profits of the firms are:

$$
\begin{aligned}
& \text { (1) } \Pi_{I}=(N-n)\left(p_{I}-c_{I}\right) x_{I}^{M}+n\left(p_{I}-c_{I}\right) x_{I}^{D}-\bar{F}_{I} \\
& \text { (2) } \Pi_{E}=n\left(p_{E}-c_{E}\right) x_{E}-\int_{0}^{n} F_{E}(\tau) d \tau
\end{aligned}
$$

$\mathrm{E}$ is the second mover in the price game. If firm I charges a price $p_{I}$, the profit maximizing price $p_{E}^{*}\left(p_{I}\right)$ and the optimal coverage $n^{*}\left(p_{I}\right)$ are found by solving: 


$$
\begin{aligned}
& \frac{\partial \Pi_{E}}{\partial p_{E}}=\left(p_{E}^{*}-c_{E}\right) \frac{\partial x_{E}}{\partial p_{E}}+x_{E}=0 \\
& \frac{\partial \Pi_{E}}{\partial n}=\left(p_{E}^{*}-c_{E}\right) x_{E}-F_{E}\left(n^{*}\right)=0
\end{aligned}
$$

The price charged by E maximizes the per-address profit and the area covered consists of all addresses for which the per-address profit is larger than the fixed delivery cost. We will assume that prices are strategic complements ${ }^{7}: d p_{E}^{*} / d p_{I}>0$. This implies that an increase in $p_{I}$ increases the market coverage of $\mathrm{E}$.

Welfare: The welfare is the sum of the consumer surplus and the firm's profit minus the subsidies. Subsidies have a shadow cost of $\lambda$ lambda meaning that transferring one Euro to the USP reduces the welfare by $1+\lambda$ Euros. The welfare is:

$$
\begin{aligned}
& W=\left(N-n^{*}\right) U\left(x_{I}^{M}, 0\right)+n^{*} U\left(x_{I}^{D}, x_{E}^{D}\right)-c_{I}\left(\left(N-n^{*}\right) x_{I}^{M}+n^{*} x_{I}^{D}\right)-c_{E} n^{*} x_{E}^{D} \\
& \quad-\bar{F}_{I}-\int_{0}^{n^{*}} F_{E}(\tau) d \tau-(1+\lambda) S
\end{aligned}
$$

Where $S=\operatorname{Max}\left[0,-\Pi_{I}\right]$ and $p_{E}^{*}$ and $n^{*}$ are given by (3) and (4).

\section{The four stages}

Monopoly USP: At an initial stage, the market is not yet open to competition and firm I operates as a monopolist. We assume that before FMO, the regulator imposes a price $\bar{p}_{I}$ that maximizes the welfare while guaranteeing a non-negative profit for firm I. The efficient price is the solution of: $\max _{p_{I}} W$ subject to $\Pi_{I}=0$ and $n^{*}=0$.

\section{FMO with pre-FMO prices}

In a second stage, the market is opened to competition but the regulator continues to impose the pre-FMO price $\bar{p}_{I}$. The price charged by $\mathrm{E}$ and its coverage are: $p_{E}^{*}\left(\bar{p}_{I}\right)$ and $n^{*}\left(\bar{p}_{I}\right)$ (see equations 3 and 4). Since firm I realizes a zero-profit at price $\bar{p}_{I}, S>0$ (equivalently $\left.\Pi_{I}<0\right)$ after FMO.

\section{FMO with profit-maximizing prices}

In a third stage, the regulator allows firm I to set freely its price. Anticipating the reaction of $\mathrm{E}$ at price $p_{I}$, I determines its price by solving:

$$
\max _{p_{I}} \Pi_{I}=n^{*}\left(p_{I}-c_{I}\right) x_{I}^{D}+\left(N-n^{*}\right)\left(p_{I}-c_{I}\right) x_{I}^{M}-\bar{F}_{I}
$$

The first order conditions read as follow:

$$
\begin{aligned}
& \frac{\partial \Pi_{I}}{\partial p_{I}}=n^{*}\left[\left(p_{I}-c_{I}\right)\left(\frac{\partial x_{I}^{D}}{\partial p_{I}}+\frac{\partial x_{I}^{D}}{\partial p_{E}} \frac{\partial p_{E}}{\partial p_{I}}\right)+x_{I}^{D}\right]+\left(N-n^{*}\right)\left[\left(p_{I}-c_{I}\right) \frac{\partial x_{I}^{M}}{\partial p_{I}}+x_{I}^{M}\right] \\
& +\frac{\partial n^{*}}{\partial p_{I}}\left[\left(p_{I}-c_{I}\right)\left(x_{I}^{D}-x_{I}^{M}\right)\right]=0
\end{aligned}
$$

The first two terms are a linear combination of the profit maximizing conditions under duopoly and monopoly. The weights given to these two conditions depend on the market coverage of $\mathrm{E}$. If we ignore the last term, we can show that the optimal price lies in between 
the optimal duopoly price ${ }^{8}$ (found by solving $\left.\left(p_{I}-c_{I}\right)\left(\frac{\partial x_{I}^{D}}{\partial p_{I}}+\frac{\partial x_{I}^{D}}{\partial p_{E}} \frac{\partial p_{E}}{\partial p_{I}}\right)+x_{I}^{D}=0\right)$ and the optimal monopoly price 9 (found by solving $\left(p_{I}-c_{I}\right) \frac{\partial x_{I}^{M}}{\partial p_{I}}+x_{I}^{M}=0$ ). And clearly, the larger is E's market coverage, the closer is the price to the duopoly price. But there is a third term in the first-order condition that captures the fact that a change in price will induce $\mathrm{E}$ to change its market coverage. In particular, if I raises its price, the per-address profit of $E$ increases and so does the market coverage.

Since $x_{I}^{D}<x_{I}^{M}$, this third term is negative and therefore it contributes to reduce the price charged by a profit-maximizing Incumbent. In other words, the optimal price for I will be lower once it takes into account the impact of its pricing decision on the area covered by $E$.

But how important is this effect. To capture that, we must turn back to the equation giving the optimal value of $n^{*}$. Re-writing (4), we have: $n^{*}=F_{E}^{-1}\left(\left(p_{E}^{*}-c_{E}\right) x_{E}\right)$, where $F_{E}^{-1}$ is the inverse of $F_{E} . F_{E}^{-1}$ is an increasing function of $p_{I}$ meaning that any price increase by the USP leads to a higher coverage by E. This seriously limits the possibility for the USP to raise its price in a competitive market. The flatter $F_{E}(n)$, the larger the increase in market coverage by E following a price increase. Clearly the distribution of the fixed cost, described by the function $F_{E}(n)$ has a central importance in determining the evolution of prices after FMO.

\section{FMO with welfare-maximizing price}

In the last stage, the regulator imposes a welfare maximizing price to I. This price is the solution of: $\max _{p_{I}} W$, taking into account the impact of $p_{I}$ on the price and the coverage of $\mathrm{E}$. The first order condition read as follow:

$$
\frac{\partial W}{\partial p_{I}}=n^{*}\left[\frac{\partial W}{\partial x_{I}^{D}}\left(\frac{\partial x_{I}^{D}}{\partial p_{I}}+\frac{\partial x_{I}^{D}}{\partial p_{E}} \frac{\partial p_{E}}{\partial p_{I}}\right)\right]+\left(N-n^{*}\right)\left[\frac{\partial W}{\partial x_{I}^{M}} \frac{\partial x_{I}^{M}}{\partial p_{I}}\right]+\frac{\partial W}{\partial n^{*}} \frac{\partial n^{*}}{\partial p_{I}}=0
$$

Equation (6) is similar to (5). This first order condition is a linear combination of the one that apply in stage 1 when the USP is a monopolist and the one that would apply in the duopoly case. There is, in addition, a third term that captures the impact of the USP price on E's coverage. If the welfare under duopoly is higher than the welfare under monopoly, this third term is positive and, it will contribute to increase the price and the market coverage. If the welfare is higher when the USP remains a monopolist, this third term is negative and it will contribute to decrease the price and E's coverage.

\section{References}

Boldron F., Joram D., Martin L. and Roy B., (2007). «From Size of the Box to the Costs of Universal Service Obligation: A Cross-Country Comparison», in M. A. Crew a P. R. Kleindorfer (eds), Liberalization of the Postal and Delivery Sector, Edward Elgar, Cheltenham.

Bloch, F. and A. Gautier (2007) - «Access, Bypass and Productivity Gains in Competitive Postal Markets», paper presented at $15^{\text {th }}$ Conference on Postal and Delivery Economics, Semmering, Austria, May 30-June 2, to appear in the conference volume edited by M. Crew and P. Kleindorfer. 
Crew, M. and P. Kleindorfer (2005) - «Competition, Universal Service and the Graveyard Spiral», in M. A. Crew a P. R. Kleindorfer (eds), Regulatory and Economics Changes in the Postal and Delivery Sector, Kluwer Academic Publishers.

d'Alcantara G. and B. Amerlynck (2006) - «Profitability of the Universal Postal Service Provider in a Free Market with Economies of Scale in Collect and Delivery», in M. A. Crew a P. R. Kleindorfer (eds), Progress toward liberalization of the Postal and Delivery Sector, Springer. Annex on ttp://www.alcantara.be/belgium/Antwerp.htm.

De Donder P., Cremer H., Dudley P. and Rodriguez F., (2006) - «A Welfare Analysis of Price Controls with End-to-End Mail and Access Services. ", in M. A. Crew a P. R. Kleindorfer (eds), Liberalization of the Postal and Delivery Sector, Edward Elgar

PricewaterhouseCoopers, (2006), "The Impact on Universal Service of the Full Market Accomplishment of the Postal Internal Market in 2009», Report to the European Commission. http://ec.europa.eu/internal_market/post/doc/studies/2006-impact-report_en.pdf.

\footnotetext{
1 http://eur-lex.europa.eu/LexUriServ/site/en/com/2006/com2006 0594en01.pdf based on the study by the E.C. to be found in http://eur-lex.europa.eu/LexUriServ/site/en/com/2006/com2006 0596en01.pdf

2 http://eur-lex.europa.eu/LexUriServ/LexUriServ.do?uri=CELEX:31997L0067:EN:HTML

3 http://eur-lex.europa.eu/LexUriServ/site/en/oj/2002/1 176/1 17620020705en00210025.pdf

${ }^{4}$ If this operation is cheap enough for the sender, it could justify that the demand addressed to the Entrant is independent of its market coverage.

${ }^{5}$ Bloch and Gautier (2007) show that high delivery costs mean that the Entrant is likely to choose the access option for mail delivery.

${ }^{6}$ But the payment required is so high that up to now, no competitor has entered the market (Price Waterhouse Coopers, 2006).

${ }^{7}$ The linear demand functions used in the calibration exercise satisfied that assumption.

${ }^{8}$ The price that firm I would have charged if $n^{*}=N$.

${ }^{9}$ The price that firm I would have charged if $n^{*}=0$.
} 